\title{
Optimasi Sumur Gas Lift XX Dengan Nodal Analysis Di PT Pertamina EP ASSET 2 Field Prabumulih
}

\author{
Faazir Aal Dito Maulana \\ Politeknik Energi dan Mineral Akamigas, Blora
}

\begin{abstract}
ABSTRAK
Sumur XX merupakan salah satu sumur minyak di Lapangan Prabumulih yang berproduksi secara sembur buatan (continuous gas lift). Saat ini, sumur XX berproduksi pada laju alir 775 blpd, laju alir gas injeksi sebesar 0.3 mmscfd, tekanan kick off sebesar 560 psi tekanan surface operation sebesar 460 psi, tekanan resevoir 2200 psi, GLR formasi $193 \mathrm{scf} / \mathrm{bbls}$ dan 95\% watercut. Dari hasil analisis nodal, didapatkan laju alir optimum sumur sebesar 895 blpd pada laju alir gas injeksi sebesar 1 . mmscfd. Penentuan gas lift spacing di dapat 6 valve yaitu 5 unloading valve dan 1 check valve dengan ukuran port 16/64 inch.
\end{abstract}

\section{PENDAHULUAN}

Minyak dan gas bumi atau sering disebut sebagai fluida hidrokarbon dan merupakan energi yang bersifat habis dipakai (non renewable) dan terdapat di batuan reservoir yang jaraknya ribuan feet dibawah permukaan tanah. Pengangkatan fluida hidrokarbon dari dalam sumur ke permukaan dapat dilakukan dengan dua cara, yaitu sembur alam (natural flow) dan pengangkatan buatan (artificial lift). Metode sembur alam terjadi apabila tenaga alamiah yang dimiliki oleh reservoir masih mampu untuk mendorong fluida ke permukaan sedangkan metode pengangkatan buatan dilakukan bila tenaga alamiah yang dimiliki oleh reservoir sudah tidak mampu lagi untuk mendorong fluida ke permukaan. Metode pengangkatan buatan yang umum digunakan pada industri minyak bumi adalah Electric Submersible Pump (ESP), Sucker Rod Pump (SRP) dan Gas Lift.

Gas lift merupakan salah satu artificial lift yang prinsip kerjanya adalah menginjeksikan gas ke dalam sumur untuk meringankan kolom fluida sehingga fluida sumur dapat dialirkan keatas permukaan. Lapangan PT PERTAMINA EP Asset 2 Prabumulih, merupakan salah satu industri minyak di Sumatera Selatan yang cukup banyak menggunakan metode gas lift sebagai metode produksinya. Hal ini yang membuat penulis tertarik untuk menyusun skripsi mengenai optimasi menggunakan analisis nodal untuk menentukan laju alir gas injeksi optimum secara ekonomis di lapangan.

Dalam memproduksikan minyak dari dalam reservoir ke atas permukaan, maka kondisi optimum merupakan kondisi yang paling tepat direncanakan untuk sumur-sumur yang berproduksi agar tidak terjadi masalah-masalah dalam memproduksikan minyak. Pada sumur gas lift, laju produksi minyak yang optimum dapat dicapai dengan menentukan injeksi gas yang optimum pula. Penentuan injeksi gas yang optimum dapat dilakukan dengan menggunakan aplikasi sistem nodal. Dengan demikian, rumusan masalah pada penulisan skripsi ini adalah: 
- Bagaimana menganalisis kondisi aktual sumur.

- Bagaimana cara menentukan laju injeksi yang optimum untuk memperoleh laju produksi yang optimum.

- Bagaimana menentukan design gas lift valve spacing.

\section{METODE}

\section{Subjek Penelitian}

Subjek dalam penelitian ini adalah kondisi aktual sumur gas lift.

\section{Objek Penelitian}

Objek dalam penelitian ini adalah besarnya laju alir cairan yang didapat berdasarkan injeksi gas.

\section{Tahapan Penelitian}

Berikut ini tahapan-tahapan yang akan digunakan penulis selama melakukan penelitian:

1. Studi pustaka

2. Penentuan laju alir gas injeksi optimum dan laju alir cairan optimum

3. Penentuan spacing katub gas lift

\section{Pengumpulan Data}

Data-data yang diperlukan untuk melakukan penelitian meliputi:

1. Data reservoir

2. Data sumur

\section{Pengolahan Data}

Data akan dianalisis dan diolah dalam bentuk tabel maupun grafik dengan menggunakan microsoft excel serta referensi dari PIPESIM.

\section{Penyajian Data}

Data yang sudah diolah, disajikan dalam bentuk hasil analisis, tabel serta grafik yang dijadikan dasar dalam penentuan laju alir gas injeksi dan laju alir cairan optimum, serta desain setelah dioptimasi.

\section{HASIL}

Sebelum melakukan perhitungan dalam perencanaan kapasitas rig yang akan digunakan. Terlebih dahulu mengevaluasi kondisi aktual. Dari data tersebut, bisa diketahui apakah sumur perlu dilakukan optimasi produski. Lalu, dilakukan perhitungan Gas Lift Performance Curve (GLPC) untuk mendapatkan laju alir gas injeksi dan lahu alir cairan yang optimum untuk 
kondisi sumur terpasang kemudian dilakukan perhitungna spacing katub gas lift hasil optimasi. Untuk data yang dijadikan dasar perhitungan menggunakan salah satu sumur yang ada di PT. Pertamina EP Asset 2 Field Prabumulih dengan rincian dan perhitungan desain sebagai berikut:

\section{Data Sumur Terpasang}

\begin{tabular}{|c|c|c|c|c|c|}
\hline $\begin{array}{l}\text { Port } \\
\text { Size }\end{array}$ & $\begin{array}{c}\text { Depth of } \\
\text { Valve }\end{array}$ & $\begin{array}{l}\text { Well } \\
\text { Temp } \\
\text { @Valve } \\
\text { Depth }\end{array}$ & $R$ Values & 1-R Values & $\begin{array}{c}\text { Injection } \\
\text { Rate }\end{array}$ \\
\hline inch & $\mathrm{ft}$ & $\mathrm{F}$ & \multirow{7}{*}{0.1534} & \multirow{7}{*}{0.8466} & \multirow{7}{*}{$0.3 \mathrm{mmscfd}$} \\
\hline $16 / 64$ & 1150 & 162 & & & \\
\hline $16 / 64$ & 2146 & 185 & & & \\
\hline $16 / 64$ & 2897 & 202 & & & \\
\hline $16 / 64$ & 3455 & 214 & & & \\
\hline $16 / 64$ & 3861 & 223 & & & \\
\hline $16 / 64$ & 4147 & 230 & & & \\
\hline
\end{tabular}

Gambar 3.1 Data Sumur XX

\section{Data Reservoir}

$\begin{array}{ll}\text { Pwh } & : 100 \mathrm{psi} \\ \text { SBHP } & : 2200 \mathrm{psi} \\ \text { FBHP } & : 1800 \mathrm{psi} \\ \text { Q Liquid } & : 775 \mathrm{blpd} \text { (existing) } \\ \text { GLRf } & : 193 \mathrm{scf} / \mathrm{bbl} \\ \text { Water cut } & : 95 \%\end{array}$

Dari data diatas, dapat kita ketahui kurva IPR vs TPR sumur XX:

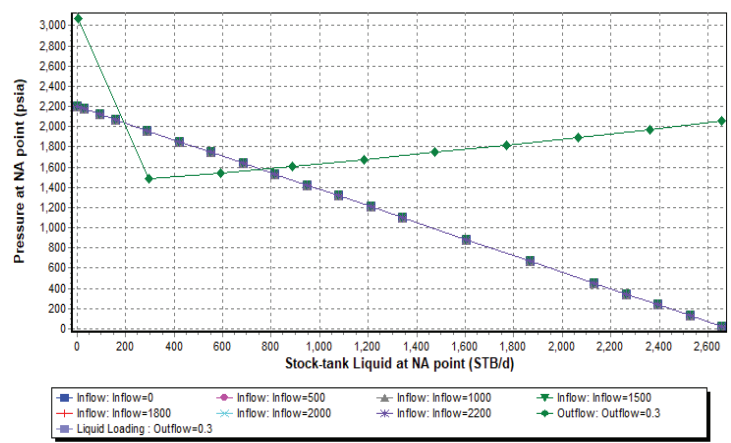

Gambar 3.2 IPR vs TPR

Dari kurva diatas diketahui laju produksi existing sumur XX hanya 45\% dari IPR menunjukkan sumur masih bisa dioptimasi.

\section{Optimasi Sumur}

Untuk melakukan optimasi sumur perlu dicari terlebih dahulu Gas Lift Performance Curve (GLPC) untuk mencari nilai laju alir gas injeksi dan laju alir cairan optimum. Dari software PIPESIM dengan dua sensitivitas Pso 460 dan 610 psi didapat kurva GLPC sumur XX sebagai berikut: 


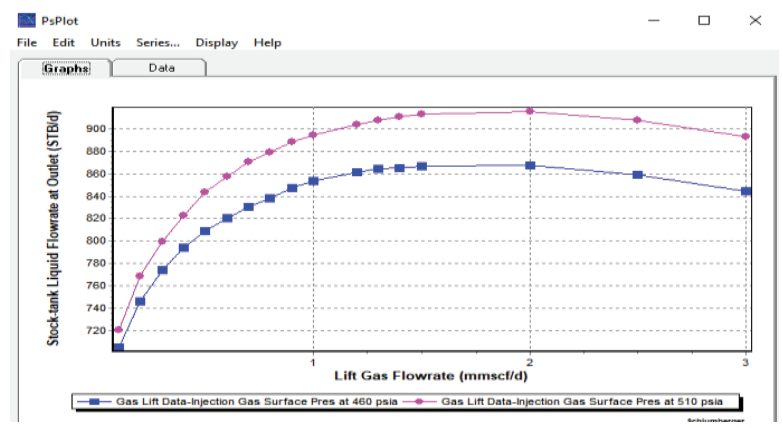

Gambar 3.3 GLPC Sumur XX

Berdasarkan grafik GLPC diatas didapatkan laju alir cairan optimum sebesar 950 blpd pada gas injeksi sebesar 1.9 mmscfd dengan Pso sebesar 510 psi, namun karena gas injeksi yang tersedia dilapangan sebesar 1 mmscfd maka dipilih laju alir cairan sebesar 895 blpd pada gas injeksi sebesar $1 \mathrm{mmscfd}$.

\section{Desain Setelah Optimasi}

Setelah didapatkan laju alir cairan dan gas injeksi optimum maka dilakukan redesign sumur gas lift sesuai laju alir cairan yang didapat ditentukan parameter yang digunakan untuk menentukan spacing katub gas lift seperti pada gambar berikut Design parameter dihitung berdasarkan kalkulasi sebagai berikut:

\begin{tabular}{|c|c|}
\hline Pwh & 100 \\
\hline Gradient Unloading & 0.102 \\
\hline $\mathrm{R}$ & 0.1534 \\
\hline 1-R & 0.8466 \\
\hline GTpf & 0.02262566 \\
\hline Gradient Static & 0.44 \\
\hline Temperatur gradient & 0.02262566 \\
\hline
\end{tabular}

Gambar 3.4 Well Optimation Parameter

Dari parameter diatas dihitung:

Menentukan Valve Spacing

Langkah awal yang harus dilakukan adalah menentukan jumlah katub yang digunakan didalam sumur dan spacing antar katub-katubnya.

Dari parameter diatas dihitung:

\section{Menentukan Valve Spacing}

Langkah awal yang harus dilakukan adalah menentukan jumlah katub yang digunakan didalam sumur dan spacing antar katub-katubnya. 
$\mathrm{D} v 1=\frac{P k o-P w h}{G s}$

$\mathrm{D} v 1=\frac{560-100}{0.44}$

$\mathrm{D} \mathrm{v} 1=1150 \mathrm{ft}$

$\mathrm{D} \mathrm{v} 2=\mathrm{D} v 1+$

$\frac{P s o 2(\text { etc })-(G u)(D v 1)+P w h}{G s}$

$\mathrm{D}$ v2 $=1045+$

$\frac{495-(0.102)(1150)+100}{0.44}$

$\mathrm{D} \mathrm{v} 2=2236 \mathrm{ft}$

Dengan cara yang sama didapatkan:

$\mathrm{D} \mathrm{v} 3=3036 \mathrm{ft}$

$\mathrm{D} \mathrm{v} 4=3616 \mathrm{ft}$

D v5 $=4028 \mathrm{ft}$

$\mathrm{D} v 6=4310 \mathrm{ft}$

\section{Menentukan Surface Casing Pressure}

Surface casing pressure tiap - tiap valve turun sebesar 15 psi sehingga:

$$
\begin{aligned}
& \text { Pso1 }=510 \mathrm{psi} \\
& \text { Pso2 }=495 \mathrm{psi} \\
& \text { Pso3 }=480 \mathrm{psi} \\
& \text { Pso4 }=465 \mathrm{psi} \\
& \text { Pso5 }=450 \mathrm{psi} \\
& \text { Pso6 }=435 \mathrm{psi}
\end{aligned}
$$

\section{Menentukan Tekanan Pada Casing Pada kedalaman Setiap Valve}

Untuk menentukan Pvo kita harus mencari nilai Weight of gas column pada tiap tekana Pso menggunakan grafik:

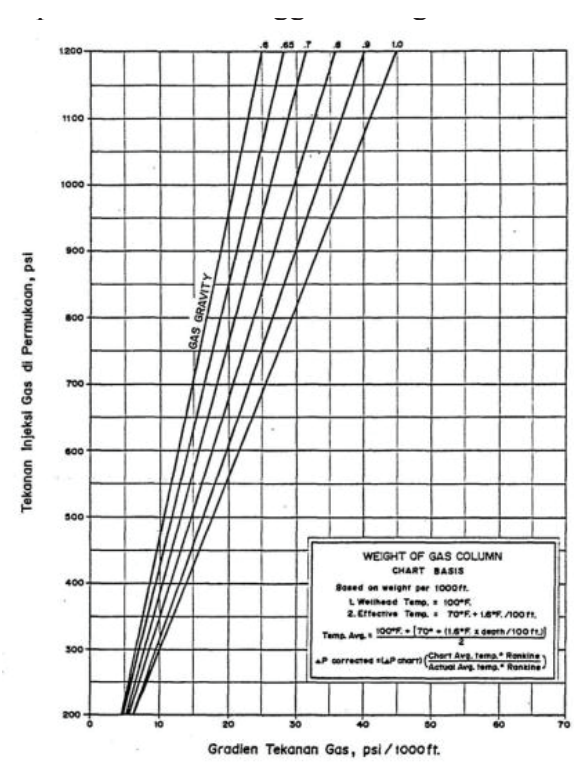

Gambar 3.5 Weight of Gas Column 


$$
\begin{aligned}
& \text { P vo1 }=\text { Pso1 }+(\mathrm{Wg})(\text { depth }) \\
& \mathrm{P} \text { vo1 }=510+(0.014)(1150) \\
& \mathrm{P} \text { vol }=526 \mathrm{psi} \\
& \text { Pvo } 2=524 \text { psi } \\
& \text { Pvo } 3=518 \text { psi } \\
& \mathrm{P} \text { vo4 }=508 \text { psi } \\
& \mathrm{P} \text { vo5 }=498 \text { psi } \\
& \mathrm{P} \text { vo6 }=485 \text { psi }
\end{aligned}
$$

\section{Menentukan Tekanan Pada Tubing}

Mencari tekanan yang ada dialam tubing pada setiap kedalaman katub

Pt $1=(\mathrm{Gu})($ depth $)+$ Pwh

Pt $1=0.102(1150)+100$

Pt $1=217$ psi

Dengan cara yang sama didapatkan:

Pt $2=328$ psi

Pt $3=410$ psi

Pt $4=469$ psi

Pt $5=511$ psi

Pt $6=540$ psi

\section{Menentukan Tekanan Pada Tubing}

Dengan OD katup sebesar 1 inch dan ukuran port 1/4 didapat nilai R sebesar 0.1534 dan 1-R sebesar 0.8466 .

Pd@tv1=Pvo (1-R)+Pt(R)

Pd@tv1=526(0.8466)+210(0.1534)

Pd@tv1=479 psi

Dengan cara yang sama didapatkan:

Pd @tv2 = 494 psi

Pd@tv3 = 501 psi

Pd@tv4=502 psi

Pd@tv5 = 500 psi

Pd@tv6=493 psi

\section{Menentukan Temperature Pada Setiap Kedalaman Valve}

Sebelum mencari temperatur pada setiap kedalaman valve terlebih dahulu dicari Flowing Temperature Gradient (Gtpf).

Gtpf $=$ 


$$
\begin{aligned}
\mathrm{Gtpf} & =\frac{T f-T w h}{\text { Totaldepth }} \\
\mathrm{Gtpf} & =\frac{303-136}{7381} \\
\mathrm{Gtpf} & =0.0226 \mathrm{~F} / \mathrm{ft}
\end{aligned}
$$

Mencari temperatur pada setiap

kedalaman valve:

$$
\begin{aligned}
\text { Tv1 } & =\text { Twh }+(\text { Depth })(\text { Gtpf }) \\
\text { Tv1 } & =136+(1155)(0.026) \\
\text { Tv1 } & =162 \mathrm{~F}
\end{aligned}
$$

Dengan cara yang sama didapatkan:

$$
\begin{aligned}
& \operatorname{Tv} 2=187 \mathrm{~F} \\
& \operatorname{Tv} 3=205 \mathrm{~F} \\
& \operatorname{Tv} 4=218 \mathrm{~F} \\
& \operatorname{Tv} 5=227 \mathrm{~F} \\
& \operatorname{Tv} 6=234 \mathrm{~F}
\end{aligned}
$$

\section{Mencari P Dome Pada Suhu $60^{\circ} \mathrm{F}$}

Untuk Mencari P dome pada temperature 60F diperlukan correction factor yang didapat dari tabel dibawah ini

FAKTOR KOREKSI TEMPERATUR UNTUK NITROGEN PADA $60^{\circ}$

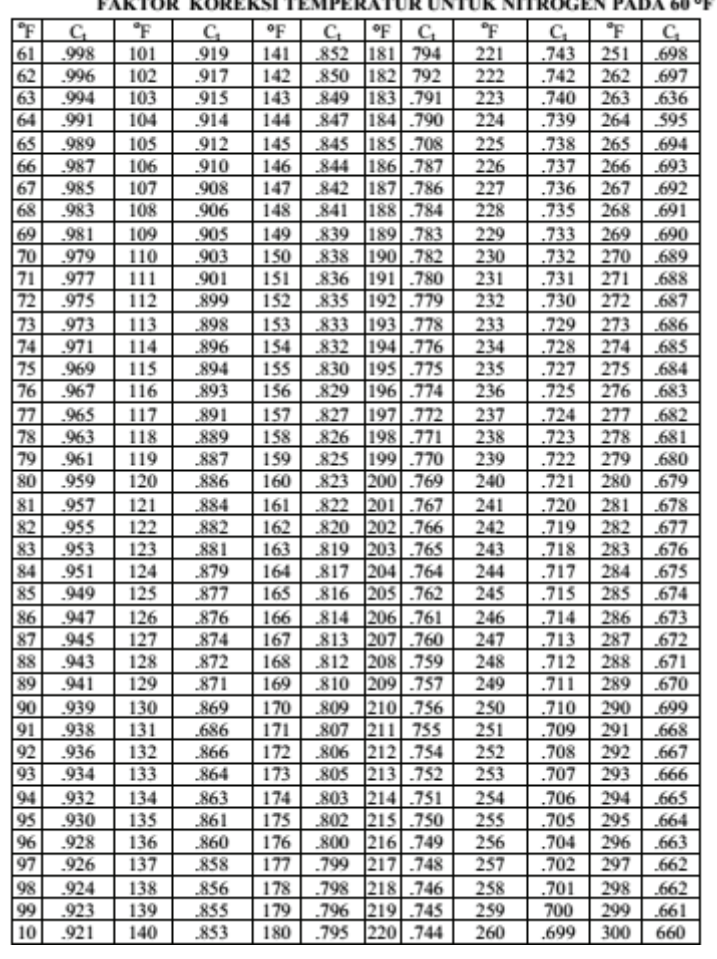

Gambar 3.6 Faktor Koreksi Suhu 
$\mathrm{Pd} @ 60 \mathrm{~F}=\mathrm{Pd} @ \mathrm{tv1}$ (correction factor)

Pd1@60F=479(0.82)

Pd1@60F =393 psi

$\mathrm{Pd} 2 @ 60 \mathrm{~F}=388 \mathrm{psi}$

$\mathrm{Pd} 3 @ \mathrm{~g} 0 \mathrm{~F}=382 \mathrm{psi}$

$\mathrm{Pd} 4 @ 60 \mathrm{~F}=375 \mathrm{psi}$

Pd5@60f = 368 psi

Pd6@60F =359 psi

\section{Mencari Test Rack Opening Pressure}

Untuk mencari tekanan buka katub pada saat di test rack menggunakan langakhar sebagai berikut:

$$
\begin{aligned}
& \text { Ptro@60F }=\frac{P d @ 60 F}{1-R} \\
& \text { Ptro1@60F }=393 / 0.8466 \\
& \text { Ptro1 = 464 psi } \\
& \text { Dengan cara yang sama diperoleh: } \\
& \text { Ptro } 2=459 \mathrm{psi} \\
& \text { Ptro } 3=451 \mathrm{psi} \\
& \text { Ptro } 4=443 \mathrm{psi} \\
& \text { Ptro } 5=435 \mathrm{psi} \\
& \text { Ptro } 6=424 \mathrm{psi}
\end{aligned}
$$

\begin{tabular}{|c|c|c|c|c|c|c|c|c|c|}
\hline $\begin{array}{l}\text { Port } \\
\text { Size }\end{array}$ & $\begin{array}{c}\text { Depth } \\
\text { OfValve }\end{array}$ & $\begin{array}{c}\text { Well } \\
\text { Temp } \\
\text { @Valve } \\
\text { Depth }\end{array}$ & $\begin{array}{r}\text { Surf( } \\
\text { Pres }\end{array}$ & & \begin{tabular}{|l|} 
Open \\
Press \\
@valve \\
depth \\
\end{tabular} & $\begin{array}{l}\text { Designed } \\
\text { tbg load } \\
\text { @valve }\end{array}$ & \begin{tabular}{|c|} 
Closing \\
or Dome \\
Press @ \\
vave \\
\end{tabular} & $\begin{array}{c}\text { Dome } \\
\text { Pressure }\end{array}$ & $\begin{array}{l}\text { Test } \\
\text { Rack } \\
\text { (Ptro) }\end{array}$ \\
\hline inch & $\mathrm{ft}$ & $\mathrm{F}$ & Open & Close & Pvo (psig) & Pt (psig & $\operatorname{Pvc}$ (psig) & psig & psig \\
\hline $16 / 64$ & 1150 & 162 & 510 & 463 & 526 & 217 & 479 & 393 & 464 \\
\hline $16 / 64$ & 2236 & 187 & 495 & 465 & 524 & 328 & 494 & 388 & 459 \\
\hline $16 / 64$ & 3036 & 205 & 480 & 463 & 518 & 410 & 501 & 382 & 451 \\
\hline $16 / 64$ & 3616 & 218 & 465 & 459 & 508 & 46 & 502 & 375 & 443 \\
\hline $16 / 64$ & 4028 & 227 & 450 & 448 & 498 & & 500 & 368 & 435 \\
\hline $16 / 64$ & 4310 & 234 & 435 & 434 & 485 & 54 & 493 & 359 & 424 \\
\hline
\end{tabular}

Dari hasil perhitungan desain sumur gas lift setelah optimasi diatas didapatkan tabel:

\section{SIMPULAN}

Saat ini, Sumur-XX berproduksi pada tekanan resevoir 2200 psi, watercut 95\%, GLR formasi 193 scf/bbls, dan Q Liquid sebesar 775 BLPD, Q gas injeksi sebesar 0.3 mmscfd.

Aplikasi sistem nodal pada sumur continuous gas lift digunakan untuk menganalisis inflow dan outflow untuk mendapatkan injeksi gas yang optimum agar memperoleh laju produksi fluida 
yang optimum pula.

Hasil perhitungan optimasi sumur di dapat laju alir gas injeksi optimum sebesar $1 \mathrm{mmscfd}$, laju alir cairan optimum 895 blpd, dan tekanan injeksi gas di permukaan (Pso) sebesar 510 psi.

Penentuan gas lift spacing di dapat 6 valve yaitu 5 unloading valve dan 1 check valve dengan ukuran port 16/64 inch.

\section{DAFTAR PUSTAKA}

Badruzzaman, Undang, 2012. “Analisis Sistem Nodal”, Cepu; PTK - Akamigas STEM.

Bradley, B., Howard, 1962. "Petroleum Engineer Handbook", Third Edition, Society Of Petroleum Engineer; USA.

Brown, E., Kermit, 1977. "The Technology of Artificial Lift Method”, Volume 1, Oklahoma; Pennwell Publishing Company.

Brown, E., Kermit, 1980. “The Technology Of Artificial Lift Method”,Volume 2a, Oklahoma; Pennwell Publishing Company.

Brown, E., Kermit, 1984. "The Technology Of Artificial Lift Method”,Volume 4, Oklahoma; Pennwell Publishing Company.

Donohue, David A.T, Ph.D, 1983. "Production Rate Decline”, Boston; International Human Resources Development Corportion Publishers

Guo, Boyun, 2007. “Petroleum Production Engineer”, Lafayette; Elsevier Science \& Technology Books.

Nurhendro, Kunto, 2011. “Teknik Eksploitasi”, Diploma 1,Cepu; PTK-Akamigas STEM.

OTIS, Gas Lift Handbook.

PIPESIM Manual Guide.

Takacs, Gabor, 2005. Gas Lift Manual. Oklahoma; Pennwell Corporation. 